\title{
Planning an interview: What do candidates want?
}

\author{
By Stacey Kimmel and Scott R. DiMarco
}

\section{Increase your chances of biring the best candidates}

$\boldsymbol{J}$ ob interviews involve considerable planning and preparation on the part of the interviewer and the interviewee. There is a sizable body of literature for job applicants who want advice on making a good impression during an interview. In contrast, there is comparatively little information for organizations on how to make a good impression on the candidate. Most of us have heard the adage that the interview is a two-way street-while we assess the candidate, the candidate assesses us. Because of the tight job market, competition for qualified candidates is keen. Top candidates may receive several job offers from prestigious institutions. Both library ${ }^{1}$ and management $t^{2}$ literature address the importance of recruitment and interview practices in attracting candidates. While the position, salary, and professional opportunities are important considerations, a candidate's perception of the coworkers, the work environment, and the surrounding community are also factored into a job decision. By tailoring the interview experience to candidate interests and needs, the library can increase the likelihood that the candidate will say yes to a job offer.

\section{The red carpet treatment}

A well-executed interview combines the art of public relations, rules of etiquette, and rituals of courtship. Planning an exceptional interview experience takes extra time and painstaking attention to detail. Why should a library roll out the red carpet for its candidates? The inter- view is an example of a small-scale project that the library has undertaken. A well-run interview suggests a well-run library. The treatment of the candidate during the interview reflects the library's attitude toward its staff and the value it places on the position. Word-of-mouth can have a powerful and far-reaching impact. A good or bad interview experience may circulate widely and affect future applicant pools.

\section{What do candidates want?}

In the recruiting literature, Rynes asserts that the recruiting representative, administrative practices, and interview procedures can be important influences on job seeker attitudes and behaviors. ${ }^{3}$ Fink, Bauer, and Campion surveyed MBA graduates on their reactions to the on-site interview. ${ }^{4}$ The candidates rated highly a) the chance to meet formally and informally with coworkers, b) tours of the community and housing, and c) tours of the work environment. Negative ratings resulted from a) repetition of interview questions, b) poor travel arrangements and accommodations c) a rushed or hectic schedule, and d) unexpected changes in the itinerary. As for the overall rating of the position, Donahue reported that candidates look primarily at the company, the management, the work environment, and the salary when evaluating a job offer. ${ }^{5}$ Of these four considerations, three are perceptions gleaned primarily from the on-site visit. These studies suggest that a well-planned interview experience can assist in the recruiting effort.

The suggestions presented below are based on a review of library and management literature, interviews with job seekers, and responses to a posting to the LIBADMIN listserv. These suggestions are especially applicable to candi- 
dates who are inexperienced at on-site interviews. For a detailed discussion on planning an interview, we suggest Managing the Interview by Susan Carol Curzon ${ }^{6}$ and the ACRL Model Statement for the Screening and Appointment of Academic Librarians Using a Search Committee. ${ }^{7}$ Finally, this article is not intended as a substitute for knowledge of federal and state laws regarding interviewing and hiring practice.

\section{Planning}

\section{Before contacting the candidate}

Assess strengths and weaknesses in the job and the organization. Use this information in recruiting efforts (e.g., if the salary is low, stress the strong benefits package or generous professional travel funding). Know your institution's internal travel/reimbursement policy and procedures.

\section{Interview arrangements}

Provide an overview of the search process and timeline for completion. If possible, give the candidate a choice of interview dates. Encourage the candidate to bring questions and concerns to your attention. Provide an e-mail adciress for making travel arrangements. E-mail is suitable for informal communications and cuts down on long-distance calls. Tell the candidate about travel reimbursement policy at your institution. Mail the information packet promptly. If travel involves an overnight stay, invite the candidate to dinner the night before or the evening after the interview. If the interview is early or late in the week, give the candidate the option of staying over the weekend. Weekend air travel is much less expensive than a one-night stay and gives candidates time to explore the surrounding community. Arrange airport pickup for air travelers if possible. Otherwise, provide approximate costs and recommendations for cabs and shuttles. Distribute resumes to staff well in advance of the interview date. This will allow them to review qualifications and prepare for the visit.

\section{Phone interviews}

When arranging the date and time of a phone interview, designate the time zone if appropriate. Provide the names and positions of participating staff in advance, and test the conferencing feature prior to the call. Call from a private office and avoid interruptions. Before starting the interview, have participants intro- duce themselves. Do not attempt to hold an interview over a noisy line.

\section{Candidate presentations}

If possible, give the candidate latitude in choosing the presentation topic. Suggesting a general topic or range of topics is less constraining and gives insight into the candidate's interests. Ask about equipment needs and preferences. Have technical support available before and during the presentation. Provide complete information about facilities (size of room, equipment, power, etc.). If the room is large, provide a microphone. Make sure no construction, fire drills, network/power outages, or other disruptions are scheduled for that time. Make sure all candidates have access to the same facilities.

\section{Planning the schedule}

Begin the day with a review of the schedule and note any changes. For interview sessions, designate a host who makes staff introductions and reserves time for candidate questions.

Over mealtimes, pace questioning and make sure the candidate has a chance to eat. Don't overschedule the candidate; provide short breaks between interviews. Schedule the presentation (if any) early in the day. The presentation provides a basis for future discussions and lets the candidate speak while he or she is

\section{Suggested interview packet contents}

- Library mission statement

- Interview agenda and participants

- Library annual reports, newsletters, statistics, etc.

- Library governance information

- Benefits and personnel documents

- Community information (local newspaper, housing, tourist information)

- Visitor parking sticker, if appropriate

- Maps

- Hotel phone, location, and reservation information

- Reimbursement instructions

- Presentation instructions, if any

- Work and home phone of contact (in case of travel clelay, other problem)

- Library and university brochures 




\section{Take a closer look at EBSCO!}

We're on the World Wide Web and ready to serve you with:

- Unparalleled subscription service (including online serials) from the world's leading subscription agency, with 30 electronically linked offices in 20 countries working for you

- CD-ROM reference tools and an online reference center, EBSCOhost", hosted by the world's leading information management company

- Fast, efficient document delivery from global resources in your choice of format.

\section{For all the information you need and want from a name you already know and trust: http://www.ebsco.com}

(205) 991-6600

Fax (205) 995-1636

P.O. Box 1943

FBSCO Birmingham, AL 35201-1943

INFOHALION SERVICE

THE LEADER IN INTEGRATED INFORMATION MANAGEMENT 


\section{Interview time averages}

Based on a survey of $62 \mathrm{MBA}$ graduates and their interview schedules for entry-level positions.?

$\begin{array}{ll}\text { Number of interviews in a day } & 4.67 \\ \text { Length of individual sessions } & 50 \text { minutes } \\ \text { Time with supervisor } & 2 \text { hours } 45 \text { minutes } \\ \text { Time with coworkers } & 2 \text { hours } 20 \text { minutes } \\ \text { Time with human resources staff } & 2 \text { hours } \\ \text { Time completing paperwork } & 10 \text { minutes }\end{array}$

fresh. Allow 10 minutes prior to a presentation for room setup and preparation. Provide ample time with supervisor and coworkers. Schedule a wrap-up meeting with the search committee (or committee chair) late in the day. Schedule a meeting with the personnel officer to review benefits and personnel information. Provide the candidate a stamped, addressed envelope for sending receipts for reimbursement.

\section{Internal candidates}

Plan ahead to avoid awkward encounters with an internal candidate. If a staff member is acting in the position the candidate has applied for, inform the candidate. This will permit open discussion of projects and activities related to the position. Assure candidates that the selection process is fair and unbiased. Caution library staff against discussing other candidates with the visiting candidate.

\section{The day before Arrival}

If you are meeting the candidate at the airport, arrive promptly. Carry a sign to help the candidate find you. If the candidate arrives by car, phone to touch base and review the next day's activities. Alternatively, leave a message with home and work phone numbers. Arrange for staff to have dinner and/or breakfast with the candidate.

\section{Interview day \\ General}

Designate a locked, secure place for the candidate to put any of his or her personal belongings. Use neutral phrasing in discussing the job (e.g., if you were in this position ....). Provide frequent restroom breaks. Have water available during interview sessions. Participating staff should dress professionally. Solicit the candidate's perceptions of the job and correct misunderstandings. ${ }^{8}$

\section{Tours}

Provide a tour of the work environment and the surrounding community. Gear the tour to the candidate's position and interests. Do not rush the tour. Show the candidate the office and equipment designated for the position. Limit the amount of walking required for the tour and use elevators when available.

\section{Exit interview}

Solicit applicant's perceptions and concerns regarding the position. Provide a timeline for the selection decision and tell the candidate how he or she will be contacted. Provide a contact person for the candidate to call with questions or for an update. Escort the candidate to the library entrance or to the hotel.

\section{Contacting the candidates Making an offer}

Be cautious in making promises to the candidate. After negotiations are over, accept refusal gracefully. Try to ascertain the reason for refusal. End with a gesture of goodwill.

\section{When a candidate accepts}

Offer to assist with moving, housing, and other arrangements. Describe the university appointment process and provide a timeline for the formal (written) offer. Secure equipment, furniture, and office space in time for the new staff member's arrival. As soon as the acceptance is confirmed, contact other applicants regarding their status.

\section{Contacting otber candidates}

Contact those who interviewed promptly and personally: ${ }^{10} \mathrm{Be}$ brief and positive. Recognize/ acknowledge the candidate's qualifications. If
Organizations that create exceptional interview experiences will increase the likelihood of hiring the best candidate. 
the pool was exceptionally large or exceptionally strong, share this with the candidate. Avoid comparisons of candidates (e.g., we hired someone with stronger leadership skills). Provide qualifications of the candidate hired if they are exceptional and can be stated objectively (e.g., we hired someone with more than 20 years of experience). ${ }^{11}$ Do not give the name of the person hired or share information that could be used to identify him or her. End with a gesture of goodwill.

\section{Conclusion}

The on-site interview should seek to recruit as well as select the best candidate. Candidates will appreciate small courtesies, attention to personal comfort, and activities that address their interests and concerns. Organizations that create exceptional interview experiences will increase the likelihood of hiring the best candidate for the job.

\section{Notes}

1. Alison Jago, "Join the Team! Recruiting for Information Professionals," Library Management 14 (1993): 31-34.

2. Sara L. Rynes, "Individual Reactions to
Organizational Recruiting: Review," Personnel Psychology 33 (Autumn 1980): 529-42.

3. Ibid.

4. Laurence S. Fink, Talya N. Bauer, and Michael Campion, "Job Candidates' Views of Site Visits," Journal of Career Planning and Employment 54 (March 1994): 32-34.

5. Mick Donahue, What Makes a Job a Good Job?" Focus 70 (July 1993): 32-34.

6. Susan Carol Curzon, Managing the Interview: A How-to-Do-It Manual for Hiring Staff (New York: Neal-Schuman, 1995).

7. ACRL, Academic Status Committee, "Model Statement for the Screening and Appointment of Academic Librarians Using a Search Committee," CERL News 10 (November 1992): $643-45$

8. Gary N. Powell, "Effects of Job Attributes and Recruiting Practices on Applicant Decision," Personnel Psychology 37 (winter 1984): 721-31.

9. Fink, Bauer, and Campion, "Joh candidates' Views."

10. Jan Yager, Business Protocol (New York: Wiley, 1991).

11. Michael G. Aamodt, "Rejecting Applicants with Tact," Personnel Administrator 33 (April 1988): 58-60.

\section{(ULS cont. from page 243)}

ULS is a "type-of-library" section of ACRL, along with the College Libraries Section and the Community and Junior College Libraries Section. All other ACRL sections are "type-ofactivity" sections, such as Instruction or Rare Book and Manuscripts. The Activities Sections Council is a vehicle for communication to share information about programming and projects. At Midwinter, the ULS Executive Committee approved a motion to be presented to the ACRL Board that the three "type-of-library" sections be permitted to join the Activities Sections Council in order to benefit from this information sharing.

The ACRL/ULS Public Services Heads of Large Research Libraries Discussion Group welcomes all librarians who are interested in academic library public services issues to attend their meetings at ALA Annual. The Discussion Group usually meets on Sunday at 2:00 p.m. At the Washington conference topics included: 1) ways to share Web page addresses developed for library instruction and distance learning; 2) how academic libraries are han- dling complaints about explicit materials on the Web being viewed on library computers; 3) reports on how various libraries are charging for printing from full-text databases._Paula Walker

\section{Librarian's discussion group}

"Should Undergraduate Librarians Publish?" was the question examined by the Undergraduate Librarians Discussion Group at Midwinter. The discussion included brief presentations from Alice Bahr, (editor of College and Undergradu ate Libraries), Mark Watson, (Southern Illinois University), and Jim Self (University of Virginia) Presenters and group members affirmed the value of publication as a contribution to the profession and to the librarian's own professional development, and emphasized the unique perspective undergraduate librarians have to offer. The discussion also delved into practical issues such as identifying appropriate journals, the logistics of writing, the varying demands of faculty status and academic status appointments, and the review process.-Linda TerHaar 


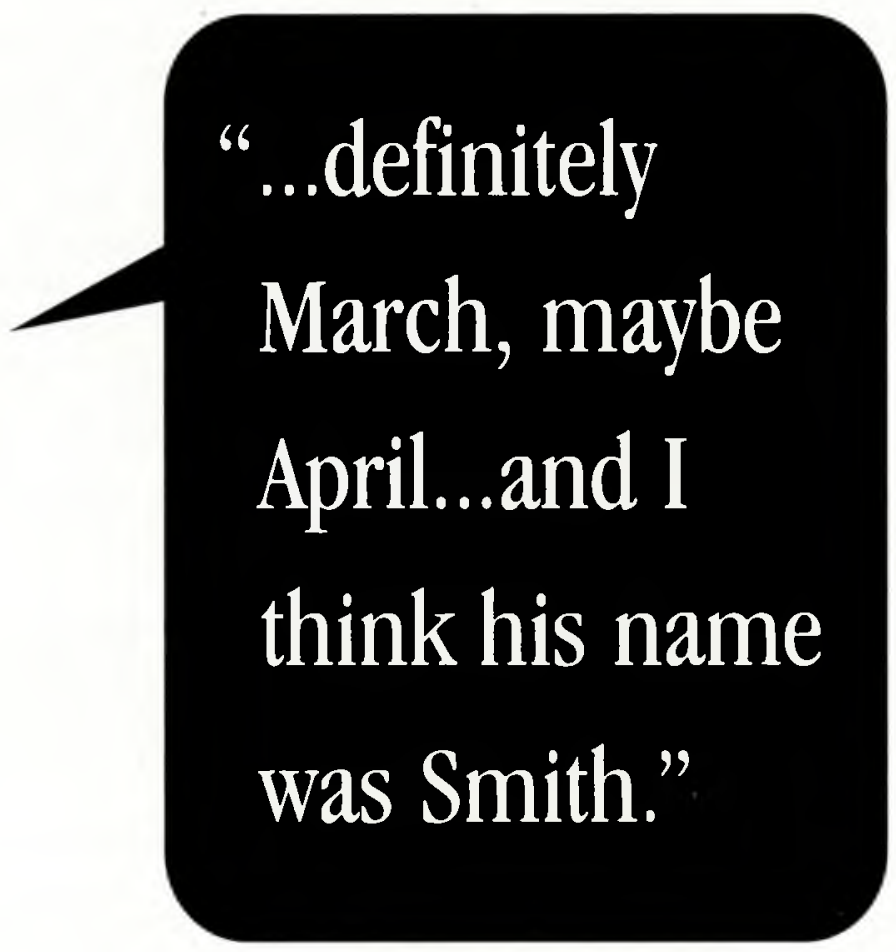

How many times have you heard that one?

Next time - and there will be a next time don't cringe. Just reach for Index to Scientific \& Technical Proceedings ${ }^{\mathrm{TM}}$ on CD-ROM or Index to Social Sciences \& Humanities Proceeding ${ }^{\top \mathrm{M}}$ on CD-ROM from ISI ${ }^{\circledR}$.

These comprehensive resources cover every significant detail from every important international conference. Conference and paper titles, dates and locations, sponsors, author and publisher names and addresses - even ISSNs/ ISBNs, prices, LC numbers, and more.

And because the software is specially designed to meet the unique demands of searching

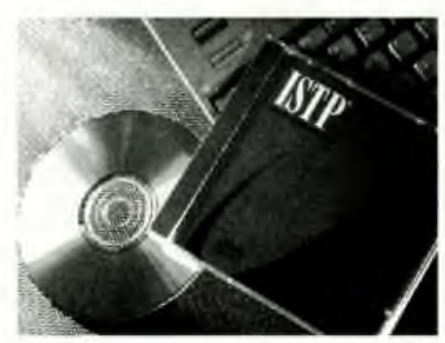

the conference literature, you'll easily uncover the exact information you need.

Plus, ISTP $P^{\mathrm{im}}$ on CD-ROM and ISSHP $P^{\mathrm{im}}$ on CD-ROM are rolling, five-year files* — each updated quarterly on one disc. So you can quickly pinpoint valuable retrospective information, as well as recently published data.

Try ISTP on CD-ROM and ISSHP on CD-ROM and perform your most efficient proceedings searches ever. No matter how sketchy or vague the clues. Call ISI today for a subscription or FREE sample.

* ISSHP on CD-ROM will cumulate as space allows. In 1997, this is an 8 year file

\section{LSI.}

\section{Institute for Scientific Information ${ }^{\mathrm{SM}}$}

3501 Market Srreet, Philadelphia, PA 19104 U.S.A. 215-386-0100; 1-800-336-4474

Brunel Science Park, Uxbridge UB8 3PQ, United Kingdom +44-1895-270016

http://www.isinet.com 